\title{
Perception of Cyberbullying in Adolescence: A Brief Evaluation Among Italian Students
}

\author{
Valeria Saladino ${ }^{*}$, Stefano Eleuteri², Valeria Verrastro ${ }^{3}$ and Filippo Petruccelli ${ }^{4}$ \\ ${ }^{1}$ Department of Human Sciences, Society and Health, University of Cassino and Southern Lazio of Cassino, Cassino, Italy, \\ ${ }^{2}$ Department of Psychology, Sapienza University of Rome, Rome, Italy, ${ }^{3}$ Department of Medical and Surgical Sciences, \\ University "Magna Graecia" of Catanzaro, Catanzaro, Italy, ${ }^{4}$ Faculty of Economics, Mercatorum University, Rome, Italy
}

\section{OPEN ACCESS}

Edited by: Rosalba Morese University of Italian Switzerland, Switzerland

Reviewed by: Nadia Crescenzo,

University of Salerno, Italy Stefano Ruberto,

University of Turin, Italy

${ }^{*}$ Correspondence:

Valeria Saladino

v.saladino@unicas.it; valeriasaladino26@gmail.com

Specialty section:

This article was submitted to Educational Psychology, a section of the journal Frontiers in Psychology

Received: 16 September 2020 Accepted: 19 October 2020 Published: 25 November 2020

Citation:

Saladino V, Eleuteri S, Verrastro V and Petruccelli F (2020) Perception of Cyberbullying in Adolescence: A Brief

Evaluation Among Italian Students. Front. Psychol. 11:607225. doi: 10.3389/fpsyg.2020.607225
Cyberbullying is associated with the expansion of digital devices and the Internet. In Italy and other European and non-European countries, the phenomenon is growing. Young people who suffer from cyberbullying develop psychopathological symptoms of anxiety, depression, and social phobia that can lead to extreme acts, such as suicide. The pressure, the sense of isolation, and helplessness experienced by cyber-victims also affect their family and the school context. Cyberbullying is acted through digital tools, it is often anonymous, and aims to destroy and psychologically humiliate the victim. There are various forms of cyberbullying that involve different reactions and consequences. However, few studies have focused on adolescents' perception of cyberbullying. Youths often engage in aggressive behaviors, ignoring the feelings and reactions of the victims. Based on these considerations, our article aims to provide a general overview of the spread of the phenomenon and to understand the various types of cyberbullying and its consequences on victims. We will also illustrate a brief evaluation conducted in Italian schools investigating the perception of cyberbullying in a sample of 600 Italian adolescents (11-14 years old). Our work aims to investigate the cognition and the personal perception of youths about cyberbullying and its consequences and to promote educational interventions within and outside the context of school.

Keywords: adolescence, cyberbullying, digital devices, intervention, psychological disease, suicide

\section{INTRODUCTION}

Recent technological developments have led to the progressive evolution of the human relationship concept. Voluntary access to social networks and online communities implies immediate proximity mediated by the web (Pratono, 2018; Auriemma et al., 2020). This evolution in human relations happened very quickly and mainly involved younger generations (Eleuteri et al., 2017). Parents, teachers, and adults are not always aware of the functioning, the rules, or the risks of the web and very often witness acts of violence and abuse among peers, which can end in tragic and extreme consequences.

Cyberbullying or electronic bullying is one of the well-known risks of this technological evolution and consists of voluntary and repeated actions against one or more individuals, through the use of computers and electronic devices (Aboujaoude et al., 2015). Cyberbullying is characterized by the following elements: voluntary act, the behavior is intentional and not accidental; repeated act, the behavior is repeated over time 
and not reduced to a single event; perception of damage by the victim, the victim suffers the damage inflicted; use of electronic devices, cyberbullying is carried out through the use of computers, cell phones, and other electronic means (Ferrara et al., 2018). Cyberbullying, like conventional bullying, is based on an asymmetrical power relationship exercised by the cyber-bully toward the victim (Durak and Saritepeci, 2020). The principal characteristic of cyberbullying is the anonymity guaranteed by the web, which provokes a perception of weakness and loneliness in the victims (Cao et al., 2020). Isolation from the peer group, lower self-esteem, and social anxiety are the most common consequences for cyber-victims. A cyber-bully might circulate images or send offensive messages or e-mails against a person or a group of people in order to deconstruct the perception of security of the victims, humiliating and isolating them. The persecutor who engages in online violence has a lower perception of responsibility for the suffering caused by one's behavior, underestimating the seriousness of the consequences for the victim, who feels not able to defend from virtual harassment.

In Italy, cyberbullying is one of the main discussed topics among middle and high school students. According to the Italian Observatory for Family, Social Policy, and Security, in 2017, 7\% of adolescents aged between 11 and 13 years old (specially females) had been the victim of cyberbullying once or more per month (Intrieri and Corraro, 2019). In European and non-European Countries, the rates of cyberbullying vary substantially between studies, with figures ranging from 6.5 to $72 \%$ for cyber victimization (Athanasiou et al., 2018; Baldry et al., 2018). For instance, a survey conducted in the United States in 2017 indicates that $33.8 \%$ of adolescents have reported that they were the victim of cyberbullying in their lifetime. In Brazil, in a 2017 survey on the use of the Internet by youths aged $9-17,22 \%$ reported being offended online, while $39 \%$ reported seeing someone being discriminated against. In China, research published between 2013 and 2018 indicates that cybervictimization ranges from between 14 and $57 \%$ and cyber aggression ranges from between 3 and 35\% (United Nations Educational, Scientific, and Cultural Organization, 2017). The Global school-based student health survey (GSHS), which collects data from people aged 11,13, and 15, suggests that the incidence of different types of violence and school bullying seems to change with age (Pontifical Scholas Occurrentes Foundation, 2019). Data from three national surveys in the United States (United Nations Educational, Scientific, and Cultural Organization, 2017) show that the most common forms of bullying, including verbal abuse, theft, threats, defamation, and social exclusion, tend to decrease with age, and bullying is reduced by nearly $50 \%$ between ages 14 and 18 , while cyberbullying declines at a lower rate, from 17 to $13 \%$. Other research shows that the incidence of bullying in the form of physical aggression is more diffused among primary school students, while cyberbullying occurs more among middle and high school students, increasing in the latter group. In Italy (ISTAT, 2015) data published in 2015 shows that, among mobile and/or Internet users, aged 11-17, 5.9\% of them report being bullied via messages email, chat, or social networks. In 2016, police data reported 235 cases of cyberbullying (Commissariato
PS, 2016). According to the ISTAT in 2018, $85.8 \%$ of children between 11 and 17 years old use mobile phones every day and $72 \%$ of children in the same age group use the Internet daily. Mostly girls aged between 14 and 17 years old uses mobile phones $(73.2 \%)$ and social networks (84.9\%). As a consequence, female teenagers are more likely to be the victim of cyberbullying $7.1 \%$ of girls suffer from constant harassment online, compared to $4.6 \%$ of boys. There is also a greater risk for youths aged between 11 and 13 years old who have been victims of bullying via mobile phones or the Internet once or more times a month (7\%) compared to the experiences of youths aged 14-17 (5.2\%) (ISTAT, 2019).

Given the serious diffusion of the phenomenon, in Italy cyberbullying is recognized as a crime by law 71/17 (Senato della Repubblica, 2017). The legislation provides a specific legal definition of cyberbullying and requires schools to educate children to use the Internet and to supervise the problem. According to the law cyberbullying is "any form of pressure, aggression, harassment, blackmail, insult, denigration, defamation, identity theft against minors, carried out electronically." The Ministry of Education has also implemented guidelines for the prevention of cyberbullying (Sorrentino et al., 2018) to counteract this high rate of incidence.

\section{TYPES OF CYBERBULLYING AND RISKS FOR HEALTH IN ADOLESCENCE}

Cyberbullying is a very complex phenomenon, consisting of different types of behavior, which are outlined here.

Flaming: involves sending violent and vulgar messages by an electronic device to provoke verbal conflicts between two or more people within the network. The victim is not always present (Qodir et al., 2019). Flaming occurs during a chat conversation or interactive video games. Mostly flaming is diffused within interactive games since, many times, the victims are beginners targeted by more experienced players (Sung Je et al., 2019).

Harassment: includes sending repeated and offensive messages to a specific person, causing strong psychological and emotional distress. Harassment occurs through email, messages, forums, chats, and discussion groups (Wells et al., 2019). As in traditional bullying, the victim is always in a "one down" position and suffers passively from aggression (Choi and Kruis, 2020; Moneva et al., 2020).

Cyberstalking: harassment, violence, threats, and persecutions online, toward a person to isolate and frighten them. The cyberstalker has control of their victims and virtually follows them. The persecutor can systematically try to contact the victim, sending offensive and intrusive messages (Reyns and Fissel, 2020). The cyberstalker is protected by anonymity and often uses fake profiles. This contributes to increasing the level of disinhibition (disinhibition effect) and aggression toward the victim (Algeri et al., 2019; Dhillon and Smith, 2019; Saladino et al., 2020).

Denigration: involves the distribution of false or derogatory messages toward victims, to damage their reputation or friendships. The persecutor often sends or publishes images, photographs, or videos relating to the victim (Sangwan and 
Bhatia, 2020). The spectators who receive these types of messages become passive (when they just watch) or active (when they share material with other friends).

Impersonation: occurs when a cyber-bully has access to the personal account information of the victim (name and password) and impersonates the target online, uploading negative information that damages the target's social relationships. This can take place on the target's social network account, blog, or other forms of online platforms. In more extreme cases, the cyber-bully changes the victim's password by preventing access to his/her account. The cyber-bully, using this method of aggression, endangers the victim. Furthermore, adolescents often share their passwords to demonstrate their "true friendship" and this indirectly contributes to impersonation (Koch, 2017).

Tricky or outing: The cyber-bully becomes a friend of the victim, leads him/her to share private and intimate information. After that stage, the cyber-bully spreads or utilizes the information to threaten the victim (Intrieri and Corraro, 2019).

Exclusion: is when the cyber-bully decides to exclude another user from his/her group of friends, or a particular chat or interactive game (password-protected environments). This type of behavior is called "banning." Exclusion from the group of friends is perceived as a severe type of punishment and can lead to reduced popularity among the peer group and therefore also of the perceived "power" (Willard, 2007; Menesini et al., 2012; Ashktorab and Vitak, 2016).

Happy slapping: is associated with traditional bullying, and consists of a video recorded during which the victim is filmed undergoing various forms of violence to humiliate them. The recordings can then be published online and viewed by other internet users (Željka et al., 2019).

According to a survey conducted by UNICEF (2020), victims of cyberbullying are more likely to incur alcohol and drug use and skip school than other students. They are also more likely to receive poor grades and have self-esteem and health issues. Young people who have been victims of cyberbullying are often reluctant to confide in adults. Cyberbullying could present symptoms similar to post-traumatic stress disorder, which can lead to suicide (Liu et al., 2020). Experiences of bullying and cyberbullying are often associated with the development of depression, social anxiety (Chu et al., 2018; Wang et al., 2019), and mental health problems (Fahy et al., 2016). Furthermore, cyber-victims have a worse quality of life, especially in terms of their psychological well-being and in the school environment (González-Cabrera et al., 2018). In Italy, there have been prominent media cases such as that of Carolina Picchio or Andrea Spezzacatena (Manes, 2013; Intrieri and Corraro, 2019). Carolina Picchio committed suicide after that her angry ex-boyfriend hurled insults and broadcasted videos in which the girl appeared in intimate attitudes. After weeks of taunts and verbal harassment, the 14-year-old girl threw herself from the window of her home (Polidori, 2018). Andrea Spezzacatena has a different story, which began with his mother who did not separate her son's jeans from colored garments, and some were were dyed pink. Andrea, amused by the situation, wore them to school but the classmates perceived Andrea to be strange and started to use homophobic appellatives. They created a profile on a well-known social network entitled:
"The boy with the pink pants." The insults and jokes were repeated and followed, ever heavier, until the day when one of the classmates painted offensive homophobic writing on the wall. As a result of this behavior, Andrea became desperate, grabbed a scarf, tied it around his neck until he suffocated, killing himself (Guerriero, 2020).

These examples suggest the need to recognize symptoms of distress in adolescents who might hide the strong feelings of loneliness and sadness associated with the victimization caused by this cyberbullying.

\section{THE PRESENT STUDY: ADOLESCENTS' PERCEPTION OF CYBERBULLYING AND FUTURE DIRECTIONS}

Our study explores the personal perception of cyberbullying by youths, taking into account the following types of cyberbullying: Harassment; Tricky or Outing; Denigration; Exclusion; Impersonation, with the aim to: (a) evaluate the general perception of cyberbullying motivation; (b) assess the identification process with the victim and the gender attribution of the cyberbullying acts; (c) evaluate the participants' tendency to perform cyberbullying, and (d) identify possible gender differences in the personal perception of cyberbullying. The sample examined Italian adolescents.

\section{Methods and Measure}

We recruited 600 participants, divided into 300 males (mean age 12.45; SD 0.900; age range: $11-14$ ) and 300 females (mean age 12,43; SD 0.857; age range: 11-14), recruited from five lower secondary schools in the Central South area of Italy.

The researchers explained the aims and scope of the research to children and their parents and obtained the informed consent for children, signed by the parents, and authorization from the School Director. The participants completed a questionnaire on the perception of cyberbullying, structured by the Department of Human, Social and Health Sciences of the University of Cassino and Southern Lazio. The questionnaire lasted $15 \mathrm{~min}$ and proposed five cyberbullying scenarios: (a) Harassment; (b) Tricky or Outing; (c) Denigration; (d) Exclusion; and (e) Impersonation. For each scenario, the participant was asked to answer five multiple-choice questions: (1) cyber-bully motivation; (2) the cyber-victim's reaction; (3) the cyber-victim's emotions; (4) the gender attribution of the cyberbully; and (5) their personal propensity to perform acts of cyberbullying. The study was approved by the International Review Board of the University of Cassino and Southern Lazio. Data were analyzed using Statistical Package for Social Sciences (Version 25.0, SPSS Inc., Armonk) (IBM Corp. Released, 2017). Descriptive analysis was used to evaluate the perception of cyberbullying for each scenario proposed. Furthermore, a chi-square test was used to evaluate gender differences in the attribution of cyberbullying acts (Wright, 1992).

All $p$-values were two-tailed, and the level of statistical significance was set at $p<0.05$ for all tests. 


\section{Results}

We undertook a descriptive analysis of the first question and the motivation to cyber-bully shows a strong tendency in participants who attribute the fault to the victim. Indeed, participants gave the same answer for all scenarios, affirming that the cybervictim suffers from cyberbullying because "he/she is strange and different from others."

Regarding the second question about the reaction of the cybervictim in a scenario where they experience Harassment, $30 \%$ of the sample thought that the cyber-victim did not react out of fear in the Tricky or Outing, Denigration, and Impersonation scenarios, with results of $32.8,36.2$, and $45.7 \%$, respectively. The participants thought that the cyber-victim should confide in someone (friends, parents, and/or teachers). Only the Exclusion scenario is connected to a different perception of the cybervictim' reaction: indeed, $25.2 \%$ of the participants affirm that the cyber-victim tries to contact the cyber-bully to ask for an explanation. This reaction might be associated with a lower fear toward the bully, due to the kind of violence or extremity of their behavior. Indeed, exclusion is a type of indirect violence that isolates the victim from others. Mostly, the exclusion could solicit a need for clarity and understanding among the cyber-victims, which can lead them to ask for an explanation.

In response to the third question, on the cyber-victim's emotions, the answers of participants are coherent with the contents of each scenario, demonstrating the participant's high capacity for understanding and perceive the feelings of others in different situations of cyberbullying. For instance, in the Denigration (20.9\%) and Impersonation (22.7\%) scenarios, participants thought that the cyber-victim felt rage; while in the Tricky or Outing scenario, they attribute the feeling of shame to the cyber-victim (28.2\%). In the Harassment scenario, the most frequently reported emotion was fear $(44.8 \%)$ while in the Exclusion scenario, it was sadness.

An interesting aspect arose concerning question number four, on the gender attribution of the cyberbully. Overall, the participants perceived males as more likely to commit cyberbullying than females. However, the chi-square analysis showed that the percentage of females who engage in acts of cyberbullying to be more than males in the scenarios $n$. 1 Harassment, 3 Denigration, and 5 Impersonation and was significantly higher than the male group. This perception seems to change in scenario n.2, Tricky or Outing, and in n. 4 on Exclusion, that do not involve aggression or threatening acts.
Table 1 reports the percentages of male and female participants in the attribution of cyberbullying, divided for each scenario; the chi-square and the p-value.

Finally, concerning the final fifth question on participants' tendency to perform cyberbullying, the participants affirmed that they do not commit cyberbullying, showing a strong perception about the consequences of cyberbullying.

Data from the descriptive analysis of each scenario are reported below, showing the percentage of the distribution of the answers among the sample recruited (Table 2).

\section{DISCUSSION}

This research represents the scenario of a specific sample; a preliminary investigation that aimed to generate a hypotheses that will be tested in subsequent studies ad hoc designs. The results are not generalizable and could be expanded in the future with a historical or longitudinal investigation. Data suggest that comparative future studies could look at other schools, such as those in the North of Italy, also considering the socioeconomic level and the family structure of the participants. In the last few years, there has been a surge of research on cyberbullying, investigating the diffusion and the consequences of the phenomenon. Data found a strong relation between cyber-victimization, anxiety, and depression (Chu et al., 2018; Wang et al., 2019). Furthermore, in European and non-European countries, the rate of suicide is growing, especially among adolescents (Athanasiou et al., 2018). The personal perception of cyberbullying is an important and often undervalued element. This aspect can help in understanding the motivation of cyberbullying, the identification with the cyber-victim, and the tendency to become a cyber-bully. We investigated the topic of adolescents' perception of cyberbullying taking into account the following types: harassment, tricky or outing, denigration, exclusion, impersonation.

Regarding the first objective to evaluate the general perception of cyberbullying motivation, data showed an attribution of fault to the cyber-victim, emphasizing the cognitive mechanism of dissociation between actions and consequences which can lead to a projected displacement of responsibility of the spectator toward the cyber-bully. Participants affirm that the cybervictim is targeted due to their personal characteristics and attitudes (they are strange and different from others). Concerning

TABLE 1 | Percentage of the two groups of participants (male and female), in the attribution of cyberbullying, divided for each scenario.

\begin{tabular}{|c|c|c|c|c|}
\hline \multirow[t]{2}{*}{ Same gender attribution of cyberbullying for each scenario } & \multicolumn{2}{|c|}{ Gender } & \multirow[t]{2}{*}{ Chi square $\left(\chi^{2}\right)$} & \multirow[t]{2}{*}{ p-Value } \\
\hline & Male & Female & & \\
\hline Scenario n. 1 Harassment & $91.6 \%$ & $60 \% *$ & 82.07 & $<0.01$ \\
\hline Scenario n. 2 Tricky or Outing & $73.3 \%$ & $69.7 \%$ & 0.98 & 0.31 \\
\hline Scenario n. 3 Denigration & $81.6 \%$ & $66.2 \% *$ & 18.54 & $<0.01$ \\
\hline Scenario n. 4 Exclusion & $76 \%$ & $69.3 \%$ & 3.35 & 0.06 \\
\hline Scenario n. 5 Impersonation & $81.6 \%$ & $60 \% *$ & 34.08 & $<0.01$ \\
\hline
\end{tabular}

Note: Pearson's $\chi^{2 *} p<0.01$ value. 
TABLE 2 | Perception of cyberbullying for each scenario in the total sample.

\section{Question}

\section{Scenario n.1 Harassment}

One of your schoolmates is receiving offensive messages and insults:

According to you why?

Because they are strange and different from others

The cyber-victim does not react out of fear

Fear

Male

No
$59.5 \%$

$30 \%$

$44.8 \%$

$65.8 \%$

$69.7 \%$

$58.8 \%$

$32.8 \%$

$28.2 \%$

$51.8 \%$

$76.2 \%$

If you had a reason, would you become friend of a person with the goal to spread

Because they are strange and different from others

The cyber-victim talks with someone (friends, parents, teachers)

Shame

Male

No his/her personal information online?

Scenario n. 3 Denigration

Someone is spreading online false and humiliating information about one of your schoolmates: According to you why?

Because they are strange and different from others

According to you how the cyber-victim reacts?

The cyber-victim talks with someone (friends,

$36.2 \%$ parents, teachers)

According to you what kind of emotion the cyber-victim feels?

If you had a reason, would you spread online false and humiliating information about

No

\section{Scenario n. 4 Exclusion}

Someone is excluding from chat group online one of your schoolmates:

According to you why?

According to you how the cyber-victim reacts?

According to you what kind of emotion the cyber-victim feels?

According to you the cyber-bully is a male or a female?

If you had a reason, would you delete an account or exclude from chat group online someone?

Because they are strange and different from others The cyber-victim tries to contact the cyber-bully to ask for an explanation.

Sadness

Male

No
$55.2 \%$

$25.2 \%$

$30.5 \%$

$53.3 \%$

$63.4 \%$

Scenario n. 5 Impersonation

Someone has appropriated the account of one of your schoolmates and is posting photos and messages in his/her name.

According to you why?

According to you how the cyber-victim reacts?

Because he/she is strange and different from others

$54.7 \%$

The cyber-victim talks with someone (friends,

$45.7 \%$

According to you what kind of emotion the cyber-victim feels? parents, teachers)

According to you the cyber-bully is a male or a female?

Rage

$22.7 \%$

Male

$60.7 \%$

If you had a reason, would you take over someone else's account and post photos

No

$76.5 \%$

the second objective to assess the identification process with the victim and the gender attribution of cyberbullying acts, participants had a coherent identification with the feelings and possible reactions of the cyber-victim, as shown in the results. In the global analysis of the sample, the majority of the participants attributed acts of cyberbullying to males, showing a high tendency to perceive men as more aggressive than women. With regard to the third objective to evaluate the participants' tendency to perform cyberbullying, adolescents affirmed that they would not commit any acts of cyberbullying.
Finally, concerning the last objective to evaluate the gender differences in the attribution of cyberbullying, there was a significant difference between boys and girls in the attribution of cyberbullying to their identified gender for the scenario n. 1, Harassment; n. 3, Denigration; and 5, Impersonation, all scenarios characterized by aggressive and threatening behavior. Indeed, a high percentage of both groups' participants attributed cyberbullying to males in all scenarios. Therefore, it might be assumed that there was a perception of the male gender as more aggressive and violent than female. 
According to these results, men perceive themselves to be more likely to commit cyberbullying, especially aggressive, violent and threatening types; while females perceive themselves as less likely to cyberbully, except for in scenarios n. 2 and n. 4. The Tricky or Outing scenario might be interpreted by the participants as joking with other people and the Exclusion scenario as a form of isolating someone; none of them involves the use of aggression, verbal attacks, threats, or explicit humiliation, acts often attributed to male gender. The participants could underestimate the psychological effects that all cyberbullying types have on victims.

The results of this study can be used to make recommendations to institutions, such as schools, to prevent cyberbullying and its consequences for adolescents. In recent years, school operators have re-evaluated educational and training aspects in addition to the traditional, educational, and cultural ones. Episodes of bullying, oppression, and aggression are often confused and labeled as a generic manifestation of "rudeness." To reduce cyberbullying, it is important to avoid attribution of blame and focus more on prevention. The study and the possibility to understand the phenomenon should guarantee its inclusion in the education of young people. According to these considerations, we suggest the following approaches.

Prevention. Promoting collaboration between family, school, and territory to counter the spread of cyberbullying and to provide socio-educational tools for parents, teachers, and students; implementing communication and confidence among youths and adults and developing new space to train parents and teachers in recognizing cyberbullying.

Intervention. Supporting psychologically the cyber-victims, developing face to face and online spaces to sensitize students with aggressive tendencies to the consequences and responsibility of their actions. Interventions could improve the development of communication, socialization, and interpersonal skills among

\section{REFERENCES}

Aboujaoude, E., Savage, M. W., Starcevic, V., and Salame, W. O. (2015). Cyberbullying: review of an old problem gone viral. J. Adoles. Health 57, 10-18. doi: 10.1016/j.jadohealth.2015. 04.011

Algeri, D., Gabri, S., and Mazzucchelli, L. (2019). Consulenza Psicologica Online. Esperienze Pratiche, Linee Guida e Ambiti di Intervento. Firenze: Giunti Editore.

Ashktorab, Z., and Vitak, J. (2016). "Designing cyberbullying mitigation and prevention solutions through participatory design with teenagers," in Proceedings of the 2016 CHI Conference on Human Factors in Computing Systems, San Jose, CA.

Athanasiou, K., Melegkovits, E., Andrie, E. K., Magoulas, C., Tzavara, C. K., Richardson, C., et al. (2018). Cross-national aspects of cyberbullying victimization among 14-17-year-old adolescents across seven European countries. BMC Public Health 18:800. doi: 10.1186/s12889-018$5682-4$

Auriemma, V., Iorio, G., Roberti, G., and Morese, R. (2020). Cyberbullying and empathy in the Ahe of hyperconnection: an interdisciplinary approach. Front. Sociol. 5, 1-11. students. An example of interventions focused on these principles is that of the so-called restorative schools (Gregory et al., 2016). This concept derives from restorative justice, which can be applied to the school system to manage conflicts in adolescence.

Only five different types of cyberbullying have been considered in our research, in particular, those most related to educational institutions, which are widespread among very young populations. However, phenomena such as happy slapping, flaming, and cyberstalking are also spreading, with worrying consequences. One of our future goals will be to promote research that also takes into account these types of cyberbullying, expanding this sample, and producing data to promote the psychological well-being in young adults and to support the families of both cyber-victim and cyber-bully.

\section{DATA AVAILABILITY STATEMENT}

The raw data supporting the conclusions of this article will be made available by the authors, without undue reservation.

\section{ETHICS STATEMENT}

The studies involving human participants were reviewed and approved by the Institutional Review Board, University of Cassino. Written informed consent to participate in this study was provided by the participants' legal guardian/next of kin.

\section{AUTHOR CONTRIBUTIONS}

VS, SE, and VV conceptualized the contribution. VS wrote the manuscript. SE and FP reviewed the manuscript. VS provided the critical revision processes as PI. All authors approved the submission of the manuscript.

Baldry, A. C., Blaya, C., and Farrington, D. P. (2018). International Perspectives on Cyberbullying. Prevalence, Risk Factors and Interventions. Milano: Palgrave Macmillan

Cao, W., Fang, Z., Hou, G., Han, M., Xu, X., Dong, J., et al. (2020). The psychological impact of the COVID-19 epidemic on college students in China. Psychiatry Res. 287:112934. doi: 10.1016/j.psychres.2020. 112934

Choi, J., and Kruis, N. E. (2020). Gender, self-control, and opportunity: applying the general theory of crime to online harassment. Int. J. Cyber Criminol. 14, 267-282. doi: 10.5281/zenodo.3753014

Chu, X., Fan, C., Liu, Q., and Zhou, Z. (2018). Cyberbullying victimization and symptoms of depression and anxiety among Chinese adolescents: examining hopelessness as a mediator and self-compassion as a moderator. Comp. Hum. Behav. 86, 377-386. doi: 10.1016/j.chb.2018. 04.039

Commissariato PS (2016). Una Vita da Social. Available online at: https://www.commissariatodips.it/uploads/media/Comunicato_stampa_ Una_vita_da_social_4_edizione_2017.pdf (accessed on 28 November 2017)

Dhillon, G., and Smith, K. J. (2019). Defining objectives for preventing cyberstalking. J. Bus. Ethics 157, 137-158. doi: 10.1007/s10551-017-3697-x 
Durak, Y. H., and Saritepeci, M. (2020). Examination of the relationship between cyberbullying and cyber victimization. J. Child Fam. Stud. 29, 2905-2915. doi: 10.1007/s10826-020-01768-4

Eleuteri, S., Saladino, V., and Verrastro, V. (2017). Identity, relationships, sexuality, and risky behaviors of adolescents in the context of social media. Sex. Relationsh. Ther. 32, 354-365. doi: 10.1080/14681994.2017.1397953

Fahy, A. E., Stansfeld, S. A., Smuk, M., Smith, N. R., Cummins, S., and Clark, C. (2016). Longitudinal associations between cyberbullying involvement and adolescent mental health. J. Adoles. Health 59, 502-509. doi: 10.1016/j. jadohealth.2016.06.006

Ferrara, P., Ianniello, F., and Villani, A. (2018). Cyberbullying a modern form of bullying: let's talk about this health and social problem. Ital. J. Pediatr. 44, 14. doi: 10.1186/s13052-018-0446-4

González-Cabrera, J., León-Mejía, A., Beranuy, M., et al. (2018). Relationship between cyberbullying, and health-related quality of life in a sample of children, and adolescents. Qual. Life Res. 27, 2609-2618. doi: 10.1007/s11136-018-1901-9

Gregory, A., Clawson, K., Davis, A., and Gerewitz, J. (2016). The promise of restorative practices to transform teacher-student relationships and achieve equity in school discipline. J. Educ. Psychol. Consult. 26, 325-353. doi: 10.1080/ 10474412.2014.929950

Guerriero, A. (2020). Il Ragazzo dai Pantaloni Rosa". Mamma Teresa Racconta la Storia di Andrea alle 15:00 su Prima Tivvu. Available online at: http://www.primativvu.it/il-ragazzo-dai-pantaloni-rosa-mamma-teresaracconta-la-storia-di-andrea-alle-15-00-su-prima-tivvu/ (accessed September $10)$.

IBM Corp. Released (2017). IBM SPSS Statistics for Windows, Version 25.0. Armonk, NY: IBM Corp.

Intrieri, M., and Corraro, D. (2019). Il Mondo Persecutorio La Tutela dei Minori e Delle Vittime di Atti Persecutori Seconda Edizione. Roma: Edizioni Admaiora.

ISTAT (2015). Il Bullismo in Italia: Comportamenti Offensivi e Violenti tra $i$ Giovanissimi. Available online at: http://www.istat.it/it/files/2015/12/Bullismo. pdf?title=Bullismo++tra (accessed on 28 November 2017)

ISTAT (2019). Indagine Conoscitiva su Bullismo e Cyberbullismo. Available online at: https://www.istat.it/it/files/2019/03/Istat-Audizione-27-marzo-2019. pdf (accessed September 6).

Koch, C. M. (2017). To catch a catfish: a statutory solution for victims of online impersonation. Univ. Colorado Law Rev. 88, 233-280.

Liu, C., Liu, Z., and Yuan, G. (2020). The longitudinal influence of cyberbullying victimization on depression and posttraumatic stress symptoms: the mediation role of rumination. Arch. Psychiatr. Nurs. 34, 206-210. doi: 10.1016/j.apnu.2020. 05.002

Manes, T. (2013). Andrea oltre il pantalone rosa. Napoli: Graus Editore.

Menesini, E., Nocentini, A., Palladino, B. E., Frisén, A., Berne, S., Ortega-Ruiz, R., et al. (2012). Cyberbullying definition among adolescents: a comparison across six European countries. Cyberpsychol. Behav. Soc. Netw. 15, 455-463. doi: 10.1089/cyber.2012.0040

Moneva, A., Miró-Llinares, F., and Hart, T. C. (2020). Hunter or Prey? Exploring the situational profiles that define repeated online harassment victims and offenders. Deviant Behav. 4, 1510-1523. doi: 10.1080/01639625.2020.1746135

Polidori, E. G. (2018). Carolina Picchio, Suicida a 14 Anni. Cyberbulli in Libertà. Available online at: https://www.quotidiano.net/cronaca/carolina-picchio-1. 4354245 (accessed September 8).

Pontifical Scholas Occurrentes Foundation (2019). Primo Rapporto Globale Sul Cyberbullismo. Available online at: https://www.scholasoccurrentes. org/wezum/stopcyberbullyingday/pdf/20_06_19_REPORTE\%20WEZUM_ ITALIAN.pdf (accessed September 6).

Pratono, A. H. (2018). From social network to firm performance: the mediating effect of trust, selling capability and pricing capability. Manag. Res. Rev. 41, 2040-8269.
Qodir, A., Diponegoro, A. M., and Triantoro Safaria. (2019). Cyberbullying, happiness, and style of humor among perpetrators: is there a relationship? Human. Soc. Sci. Rev. 7, 200-206. doi: 10.18510/hssr.2019.7331

Reyns, B. W., and Fissel, E. R. (2020). “Cyberstalking," in The Palgrave Handbook of International Cybercrime and Cyberdeviance, eds T. Holt and A. Bossler (Cham: Palgrave Macmillan).

Saladino, V., Algeri, D., and Auriemma, V. (2020). The psychological and social impact of Covid-19: new perspectives of well-being. Front. Psychol. 11:577684. doi: 10.3389/fpsyg.2020.577684

Sangwan, S. R., and Bhatia, M. P. S. (2020). D-BullyRumbler: a safety rumble strip to resolve online denigration bullying using a hybrid filterwrapper approach. Multimedia Syst. 26, 1-17. doi: 10.1007/s00530-02000661-w

Senato della Repubblica (2017). Law n. 71/17 of 29/05/2017, GU n. 127 of 03/06/2017. Available online at: http://www.senato.it/leg/17/BGT/Schede/ Ddliter/43814.htm (accessed on 11 September 2017)

Sorrentino, A., Baldry, C. and Cacace, S. (2018). "Cyberbullying in Italy", in International Perspectives on Cyberbullying Prevalence, Risk Factors and Interventions, eds A. C. Baldry, C. Blaya, and D. P. Farrington (London: Palgrave McMillan).

Sung Je, L., Eui Jun, J., and Joon Hyun, J. (2019). Disruptive behaviors in online games: effects of moral positioning, competitive motivation, and aggression in "League of Legends". Soc. Behav. Pers. Int. J. 47, 1-9. doi: 10.2224/sbp.7570

UNICEF (2020). Safer Internet Day: un Adolescente su tre Vittima Di Cyberbullismo. New York, NY: UNICEF.

United Nations Educational, Scientific, and Cultural Organization (2017). National Center for Injury Prevention and Control, CDC and the US Department of Education, Bullying Surveillance Among Youths: Uniform Definitions for Public Health and Recommended Data Elements, Version 1.0, 2014. School Violence and Bullying. Paris: United Nations Educational, Scientific, and Cultural Organization.

Wang, W., Xie, X., Wang, X., Lei, L., Hu, Q., and Jiang, S. (2019). Cyberbullying and depression among Chinese college students: a moderated mediation model of social anxiety and neuroticism. J. Affect. Disord. 256, 54-61. doi: 10.1016/j. jad.2019.05.061

Wells, M., Mitchell, K. J., Jones, L. M., and Turner, H. A. (2019). Peer harassment among youths with different disabilities: impact of harassment online, in person, and in mixed online and in-person incidents. Child. Schl. 41, 17-24. doi: $10.1093 / \mathrm{cs} / \mathrm{cdy} 025$

Willard, N. E. (2007). Cyberbullying and Cyberthreats: Responding to the Challenge of Online Social Aggression, Threats, and Distress. Champaign, IL: Research Press.

Wright, S. P. (1992). Adjusted P-values for simultaneous inference. Biometrics 48, 1005-1013. doi: $10.2307 / 2532694$

Željka, D., Vesna, C., Ines, R., Aleksandar, V., Zvjezdana, G., Đuro, M., et al. (2019). Cyberbullying in early adolescence: is there a difference between urban and rural environment? Am. J. Biomed. Sci. Res. 1, 191-196. doi: 10.34297/AJBSR. 2019.01.000542

Conflict of Interest: The authors declare that the research was conducted in the absence of any commercial or financial relationships that could be construed as a potential conflict of interest.

Copyright $\odot 2020$ Saladino, Eleuteri, Verrastro and Petruccelli. This is an open-access article distributed under the terms of the Creative Commons Attribution License (CC BY). The use, distribution or reproduction in other forums is permitted, provided the original author(s) and the copyright owner(s) are credited and that the original publication in this journal is cited, in accordance with accepted academic practice. No use, distribution or reproduction is permitted which does not comply with these terms. 